\title{
Health care and long-term care costs by age and proximity to death in a publicly funded universal system: A descriptive study of population data
}

\author{
JORID KALSETH ${ }^{1 *}$ \\ KJARTAN SARHEIM ANTHUN ${ }^{1}$ \\ LEENA FORMA ${ }^{2,3}$ \\ ${ }^{1}$ Department for Health Research, SINTEF Digital, Trondheim, Norway \\ ${ }^{2}$ Faculty of Social Sciences (health sciences) and Gerontology Research Center (GEREC), Tampere \\ University, Finland \\ ${ }^{3}$ Faculty of Social Sciences, University of Helsinki, Finland
}

\begin{abstract}
Trends in population ageing parallel concerns with escalating health care expenditures. The purposes of this study are to (1) estimate the distribution of health care and long-term care costs to ascertain the relative importance of age vs. proximity to death as the main driver of costs; (2) explore the relative importance of user rates and costs per user as the primary driver of per capita costs of selected services for survivors and decedents, respectively; and (3) illustrate the relative magnitude of proximity-to-death adjustment in projections of future costs. We use data on service use for the entire Norwegian population from four national registers linked with the Cause of Death Registry to calculate costs per decedent in the last 365 days of life and the average one-year costs of people surviving at least two years. Future costs were calculated using projections on population and probability of death from Statistics Norway. We find that the substantial increase in costs at older ages among both decedents and survivors relates to higher longterm care costs. Health care costs peak in the late 50s among decedents and in the early $80 \mathrm{~s}$ among survivors and then decrease with age. The decedent/survivor cost ratio decreases with age from $>20: 1$ in age groups $\geq 30$ to $<50$ year to less than double among those aged $\geq 95$ years. Expenditure projections indicate an increase in spending due to population ageing, especially in long-term care expenditures. For somatic hospital costs, proximity to death has a greater impact on costs than age; the age effect is more important for long-term care, implying that the "red herring" effect is larger for acute health care than for long-term care. Adjusting for costs during the last year of life reduces the projected increase in expenditures, but only to a limited extent.
\end{abstract}

JEL classification: $\mathrm{H} 51, \mathrm{H} 75, \mathrm{I} 110$

Key words: health care and long-term care costs, forecast expenditures, proximity to death, age distribution, population ageing

* Correspondence to: Jorid Kalseth, Department of Health Research, SINTEF Digital, P.O. Box 4760, Torgarden, NO-7465 Trondheim, Norway. Phone: +47 92885080. Email: jorid.kalseth@sintef.no.

Published: Online June 2020. dx.doi.org/10.5617/njhe.7070 


\section{Introduction}

Trends in population ageing parallel concerns with escalating health care expenditures. This stems from the observation that health care costs increase with age (Przywara 2010). This age effect could be biased upwards if population ageing is followed by lower mortality rates and the postponement of death-related costs, as increasing costs with age are likely to capture high death-related costs (Fuchs 1984). That proximity to death (PTD) and not age per se is the main driver of health care costs is referred to as the "red herring" hypothesis (i.e., age being a red herring) (Zweifel et al. 1999).

Fortunately, there is a growing body of literature on the relative importance of age vs. PTD for health care costs. While some studies conclude that age is not important once PTD is taken into account (Felder et al. 2010, Hyun et al. 2015, Yu et al. 2015) and others claim the marginal importance of PTD compared with population ageing for future health care costs (Colombier and Weber 2011, van Baal and Wong 2012), both PTD and age are typically found to be relevant (Raitano 2006). However, this may vary depending on, for instance, the disease (Wong et al. 2011) or the type of health care service under study (Atella and Conti 2014, Moore et al. 2014, Werblow et al. 2007, Häkkinen et al. 2008, Larsson et al. 2008). A particularly important distinction is between acute health care and long-term care. Whereas PTD may precede age as a determinant of individual acute health care cost, long-term care costs generally strongly increase with age (de Meijer et al. 2013).

The main purpose of this study is to take advantage of register data on individual service utilisation covering the entire Norwegian population to analyse these relations. First, we estimate and describe the distribution of health care and long-term care costs to explore the relative importance of age vs. PTD as the main driver of costs. Second, we explore the relative importance of user rates and costs per user as the primary driver of per capita costs of selected services for survivors and decedents, respectively. Third, we provide projections of future costs.

Like other Nordic countries, Norway has an universal, extensive and mainly publicly funded health care and long-term care service system (Karlsson et al. 2012). Some existing studies analyse the effect of PTD on somatic hospital costs in Norway (Gregersen and Godager 2014, Melberg et al. 2013). We augment these studies by including specialist mental health, primary care physicians, prescription drugs and long-term care services. Including long-term care is particularly important as the age effect is not only likely to be most pronounced for these services as discussed, but also because nursing homes have increasingly become an important place of end-of-life care in Norway (Kalseth and Theisen 2017). Indeed, Norway is among those countries with the highest share of deaths taking place in nursing homes (Broad et al. 2013).

Furthermore, we add to the literature by decomposing the per capita costs of the different services, thereby enabling analysis of the relative importance of differences in user rates and costs per user for differences in the average costs of decedents and survivors. This provides a far deeper understanding of the underlying factors driving health care and longterm care costs. Unlike much of the "red herring" literature we also provide cost projections to assess the magnitude of the potential bias if not adjusting for PTD when calculating the impact of the ageing population on future health spending. Since our focus is on population aging and the relative importance of age vs PTD for health care (HC) and long-term care (LTC) costs, the projections are done assuming unchanged cost levels by age and gender, i.e. disregarding factors like income, productivity, technology, organisation and policy (Marino et al. 2017). The impact of these factors is complex and closely interlinked with the demographic development. 


\section{Data and methods}

\subsection{Setting}

In Norway, municipalities are responsible for providing both primary health care and longterm care, while four state-owned regional health authorities (RHAs) are responsible for specialist (secondary) health care. Primary care physicians commonly operate in private group practices working under contract for their local municipality and serve a gatekeeping function for referral to specialist health care. Public (municipal) providers mostly provide primary nursing and long-term care services, whereas public health enterprises owned by the RHAs operate most secondary health care services, although some are owned by private providers under contract with the RHAs. Outpatient health services, both primary and specialist, as well as home care (such as practical aid but not nursing) and long-term residential care are subject to user charges. User charges cover only a small part of total costs: just $15 \%$ of total health expenditures (OECD) and only $7 \%$ of expenditures in municipal long-term care services (Hagen et al. 2011).

\subsection{Study design: Population, data sources and linkage}

Our data on service utilisation come from four different public registries (see Table S1 in the supplementary material). The registry for Control and Payment of Health Reimbursement (KUHR) covers all health care activities eligible for part reimbursement from the National Insurance Scheme. From this database, we collected data for primary health care physicians comprising general practice and emergency visits, and data for selfemployed specialists working under contract with an RHA. The Norwegian Patient Registry (NPR) covers all inpatient and outpatient specialist (secondary) health care, including somatic and psychiatric services and substance abuse treatment ${ }^{1}$. Data on long-term care are from the Norwegian Information System for the Nursing and Care Sector (IPLOS). Finally, data on prescription drugs are from the Norwegian Prescription Database (NorPD), covering individual purchases. Drug costs in hospitals and nursing homes are included in the cost estimates for the respective services.

We retrieved two different datasets from each of the four data registries. The first covers the entire Norwegian population in 2010 and is used to identify the utilisation - and thereby costs - of the total population and that of survivors. We defined survivorship as surviving at least two years (Forma et al. 2009) and linked the full population data from the registry to information from the Cause of Death Registry on whether a person died in 2010 or in one of the following two years. The second dataset comprises utilisation one year prior to death (the last 365 days of life including the day of death) for all persons dying in 2011, identified by linking information on the day of death of decedents from the Cause of Death Registry with each service registry. Hence, we compare service utilisation in the last year of life with one year of utilisation for persons alive at least two years after the chosen calendar year (2010). Unfortunately, we are unable to link information across different service registries, only each registry with the Cause of Death Registry.

In most cases, the service registries include information on utilisation and not costs. We calculate costs by multiplying the chosen unit of utilisation with an estimate of unit costs (see Table S2 in the supplementary material). In calculating per capita costs and user rates, the denominator for survivors is the population data collected from Statistics Norway (see the supplementary material). The number of decedents in 2011 draws on data from the Cause of Death Registry. In calculating the share of costs for decedents in the population

\footnotetext{
${ }^{1}$ Because the data for private specialists were not complete in 2010, we chose instead to use data from the KUHR database to calculate costs.
} 
costs, we used the number of deaths in 2010 and combined these with the costs per decedent in 2011.

The following service categories were used in the analyses (see Table S1 in the supplementary material).

- Health care (HC) with the following subcategories: primary care physicians (GPs); prescription drugs (medicine); specialist somatic care including specialist rehabilitation (somatic); and mental health care comprising specialist psychiatric and substance abuse treatment (mental health).

- Long-term care (LTC) including institutional-based and home-based nursing and social care services.

We refer to the sum of costs for HC and LTC as total costs (TC) and identify the number of unique users (persons) for each service category studied.

\subsection{Analyses}

The study provides descriptive analyses (tables and graphics) of per capita costs (average cost) by age for survivors and decedents. The analyses are for TC and separate services. We also provide a decomposition of per capita costs into costs per user and users per capita (user rate). However, as we were unable to link the data between registries, we have only decomposed the per capita costs for services within registries, that is, for the five service categories.

Age is calculated using the year of birth. We mostly use five-year age bands (20-24 years, 25-29 years, etc.), except when there are data restrictions on the number of LTC users, with children and adolescents (0-19 years) and persons aged $\geq 100$ years each comprising one group. Future cost projections for the years 2018-2040 were calculated using population projections (main alternative: median fertility, median life expectancy, and median migration and immigration) and projected probability of death (median life expectancy) from Statistics Norway (Statistics Norway. StatBank. 11168 , Statistics Norway. StatBank. 11094). In projecting unadjusted future per capita cost, we multiplied projected population numbers for the same age groups by per capita costs in 2010, with the resulting sum over age groups divided by the projected total population.

We adjust for PTD by (i) identifying non-decedents in each future year by subtracting the projected number of deaths from the projected total population for each age group, (ii) calculating the average costs of non-decedents in 2010 by subtracting the estimated costs of dying for the relevant age group and dividing by the number of nondecedents in 2010, (iii) calculating the costs of decedents and non-decedents by multiplying the average costs for each group by the projected population numbers and summarising, and (iv) dividing the sum of calculated costs over the various age groups with the projected total population number. In the calculation of future costs, we used gender-specific costs profiles.

\section{Results}

\subsection{TC per decedent and survivor}

While decedents constituted less than $1 \%$ of the population, the costs of people in their last year of life constituted $12 \%$ of estimated TC in this study (Table 1). Both the share of population and the share of costs related to death increased with age, reaching $10 \%$ of costs and the population in the early 60 s and late 80 s, respectively. Among the oldest persons 
(aged $\geq 100$ years), decedents constituted nearly $40 \%$ of the population and nearly $60 \%$ of costs.

Table 1: Decedent share (\%) of population and cost, costs per survivor and per decedent (1,000 NOK, 2010), ratio of decedent/survivor costs per capita, by age group

\begin{tabular}{|c|c|c|c|c|c|}
\hline \multirow{2}{*}{ Age group } & \multicolumn{2}{|c|}{ Decedents } & \multirow{2}{*}{$\begin{array}{c}\text { Costs per } \\
\text { survivor }(\mathrm{S})\end{array}$} & \multirow{2}{*}{$\begin{array}{c}\text { Costs per } \\
\text { decedent }(\mathrm{D})\end{array}$} & \multirow{2}{*}{ Ratio D/S } \\
\hline & $\%$ population & $\%$ cost & & & \\
\hline $0-19$ & 0.03 & 0.8 & 11.8 & 357.3 & 30.3 \\
\hline $20-24$ & 0.1 & 1.0 & 20.7 & 373.2 & 18.0 \\
\hline $25-29$ & 0.1 & 0.9 & 22.9 & 381.1 & 16.7 \\
\hline $30-34$ & 0.1 & 1.3 & 23.3 & 547.5 & 23.5 \\
\hline $35-39$ & 0.1 & 1.5 & 22.2 & 491.7 & 22.1 \\
\hline $40-44$ & 0.1 & 2.1 & 22.6 & 479.9 & 21.3 \\
\hline $45-49$ & 0.2 & 3.3 & 24.9 & 520.7 & 20.9 \\
\hline $50-54$ & 0.3 & 4.9 & 26.6 & 486.8 & 18.3 \\
\hline $55-59$ & 0.5 & 7.3 & 29.5 & 535.8 & 18.2 \\
\hline 60-64 & 0.7 & 9.8 & 32.1 & 494.9 & 15.4 \\
\hline 65-69 & 1.2 & 13.0 & 37.6 & 503.0 & 13.4 \\
\hline 70-74 & 1.9 & 15.2 & 47.8 & 495.7 & 10.4 \\
\hline 75-79 & 3.3 & 18.4 & 64.0 & 489.5 & 7.6 \\
\hline $80-84$ & 5.9 & 22.5 & 89.9 & 496.9 & 5.5 \\
\hline $85-89$ & 10.2 & 26.3 & 138.7 & 514.2 & 3.7 \\
\hline 90-94 & 17.4 & 32.9 & 211.6 & 554.3 & 2.6 \\
\hline 95-99 & 27.0 & 42.2 & 304.4 & 606.7 & 2.0 \\
\hline$\geq 100$ & 39.4 & 57.9 & 404.5 & 643.9 & 1.6 \\
\hline Total & 0.8 & 12.4 & 27.3 & 516.9 & 18.9 \\
\hline
\end{tabular}

The average costs per decedent were about 517,000 Norwegian kroner (NOK), compared with 27,000 NOK per survivor, that is, a ratio of 19:1. The average costs of decedents were lowest for age groups $<30$ years $(357,300-381,100 \mathrm{NOK})$, they were relatively similar for age groups $\geq 30$ to $<90$ years $( \pm 500,000 \mathrm{NOK})$ and they increased among the oldest age groups ( $>600,000 \mathrm{NOK}$ for $\geq 95$ years). In comparison, the average costs among survivors were $<25,000 \mathrm{NOK}$ for age groups $<50$, and while increasing with age after 50 , the curve steepened in old age from about 90,000 NOK in the early 80 s to $400,000 \mathrm{NOK}$ in the $\geq 100$ age group. In the youngest age group, $0-19$ years, costs per decedent were 30 times higher than costs per survivor. For age groups $\geq 30$ years, the decedent/survivor cost ratio decreased with age, from about $24: 1$ in the early 30 s and 10:1 in the early $70 \mathrm{~s}$, to less than five times in the late $80 \mathrm{~s}$ and less than double for the oldest age groups. The absolute difference in average costs was highest for age groups $\geq 30$ to $<85$ years $(>400,000 \mathrm{NOK})$.

\subsection{Decomposition of costs}

Figure 1 plots the age profiles of per capita costs for decedents and survivors for each service, the decomposition of per capita costs into user rates and costs per user, and the decedent/survivor ratio for the three indicators. The average costs of the services and the decedent/survivor ratio are also shown in Table S3 in the supplementary material. Except 
for relatively high mental health costs among young adults, somatic costs and LTC costs are the major cost components among both survivors and decedents, with somatic costs dominating for the middle-aged and LTC costs for those in old age. In comparison, the costs of GPs and medicine are low for all ages, while HC costs are higher than LTC costs for age groups $<80$ years.

While $\mathrm{HC}$ costs per survivor increase with age, they are relatively stable in the late 20 s to early 40 s, until reaching a maximum of around 40,000 NOK for the 75-89 age groups, with declining costs among the oldest age groups. HC costs per decedent reach a maximum of about $420,000 \mathrm{NOK}$ in the late $50 \mathrm{~s}$. For higher ages, there is a sharp decline in cost to $45,000 \mathrm{NOK}$ in the $\geq 100$ age group. Looking at different $\mathrm{HC}$ services, the peak in average decedent costs is in the 50-69 age groups for somatic costs, in the 40-59 age groups for medicine and in the early 30 s for mental health costs, while GP costs were highest and relatively stable in age groups $\geq 30$ and $<80$ years. Survivor costs peaked at a higher age than decedent costs for all HC services, except mental health.

Among both decedents and survivors, per capita LTC costs were relatively stable among the non-elderly and increased among the elderly. The relative increase was much higher for survivors than for decedents; the average costs of a survivor aged $\geq 100$ years were almost 50 times higher than for a survivor in the late $60 \mathrm{~s}$; for decedents, the relative difference was only about fourfold. The decedent/survivor cost ratios were highest for somatic care and LTC. Average somatic costs were about 40 times higher for decedents than survivors in their 40s and about three times higher in the oldest age group. For LTC, the cost ratio varied from $21: 1$ in the 30 s to $1.5: 1$ in the $\geq 100$ age group.

We find a negative age gradient among the elderly for both user rates and costs per user of the different $\mathrm{HC}$ services, starting at an earlier age among decedents than for survivors. The exception is somatic costs per user for survivors, which do not decrease among the oldest age group. Even if user rates are higher for decedents than for survivors for most services and ages, costs per user are the major source of difference in per capita costs for somatic care, GPs and medicine. For these services, costs per user are much higher for decedents than for survivors; however, user costs decline sharply with age among the middle-aged and elderly. Conversely, for mental health and LTC, user rates are more important than costs per user for differences in average cost between decedents and survivors, except for LTC costs among the oldest age group. LTC user rates are very low among non-elderly survivors and exhibit a steep increase in old age. For decedents, LTC user rates increase steadily with age. Except for the youngest age groups, costs per user for LTC display a U-shaped age pattern among both decedents and survivors, with the lowest costs per user observed at a higher age for survivors (around 80 years) than decedents (in their $50 \mathrm{~s}$ to $60 \mathrm{~s}$ ). For mental health, user rates and costs per user are considerably higher for decedents than for survivors, except among the elderly, and especially in their early $30 \mathrm{~s}$. As many as $40 \%$ of the deceased had used some mental health service in the last year of life in this age group. 
a) Costs per capita

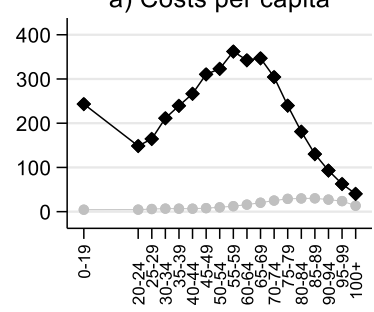

e) Costs per capita

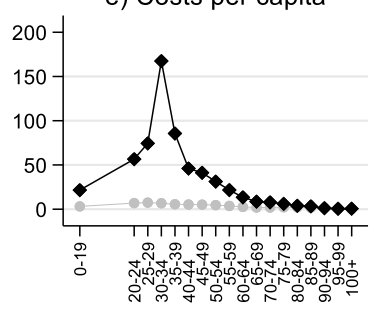

i) Costs per capita

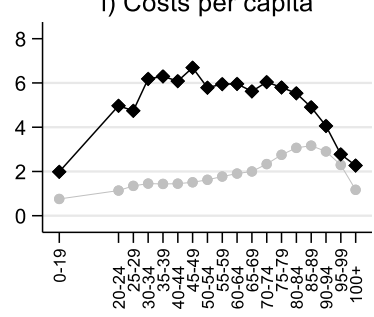

m) Costs per capita

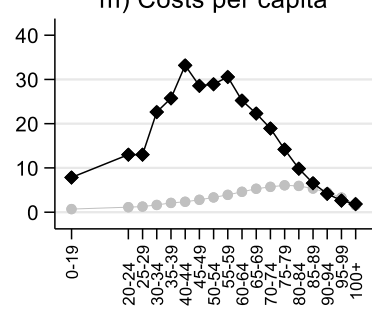

q) Costs per capita

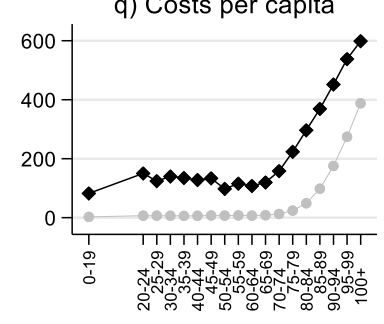

Somatic health care

b) Users per 100 capita
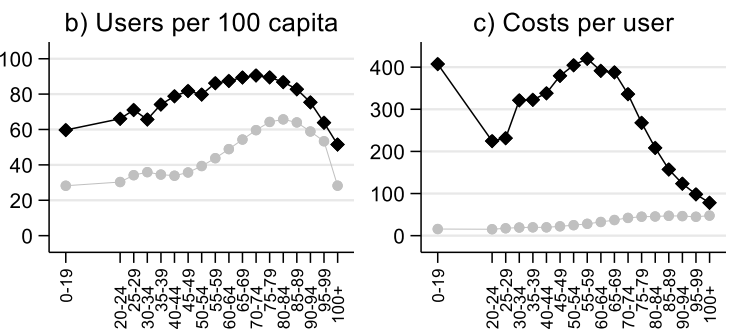

Mental health care
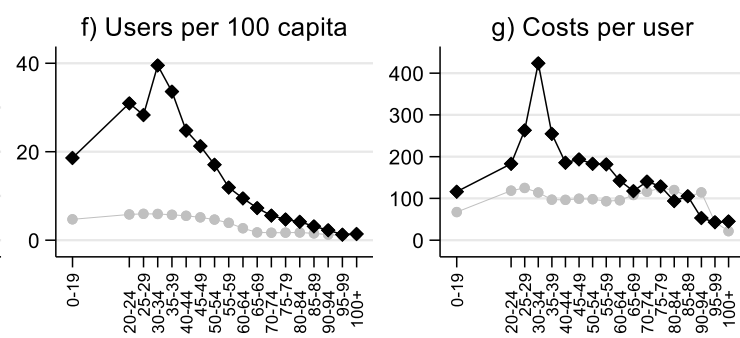

Primary care physicians
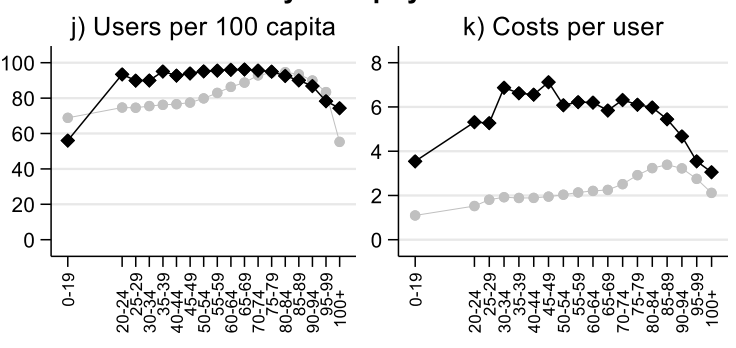

Prescription drugs

n) Users per 100 capita

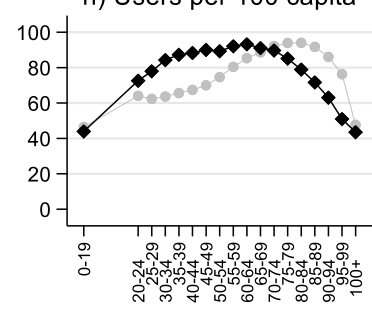

o) Costs per user
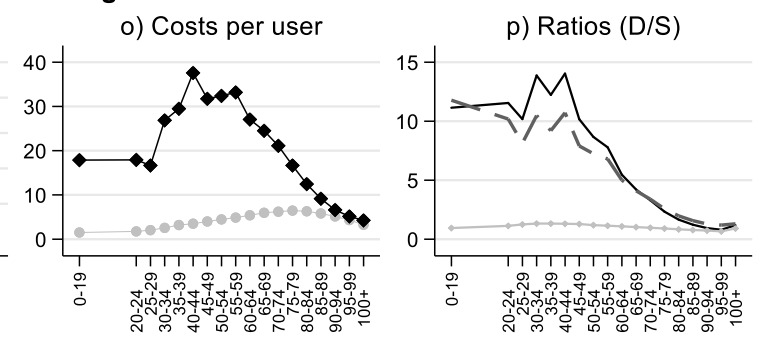

d) Ratios (D/S)

h) Ratios (D/S)

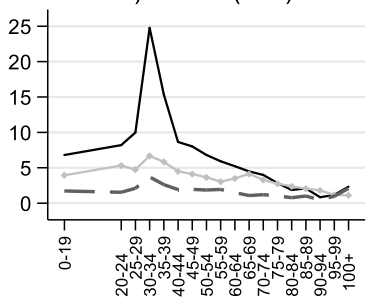

I) Ratios (D/S)

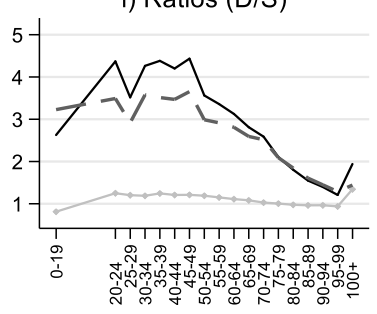

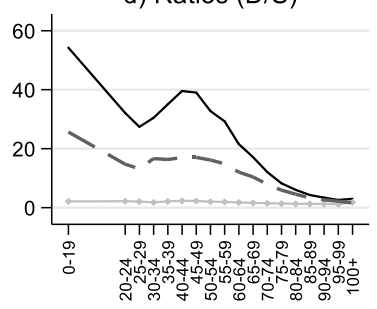

\section{Long term care}

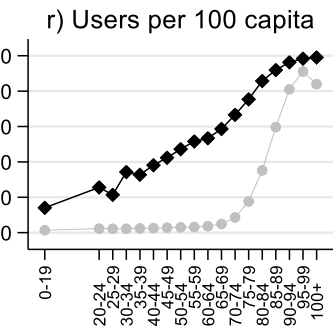

s) Costs per user

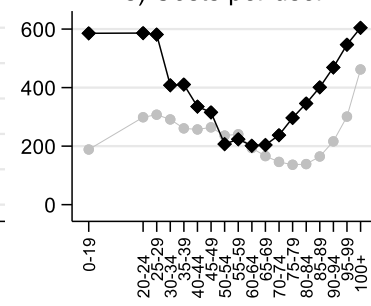

t) Ratios (D/S)

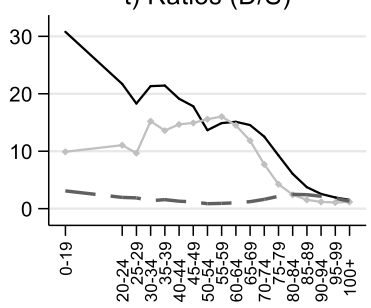

Figure 1: Costs per capita (1,000 NOK), users per capita and costs per user by age and survivorship. Ratios (decedent/survivor): costs per capita (black, no marker), users per capita (grey, marker), costs per user (grey, dashed) 


\subsection{Projections}

Figure 2(a) depicts the projected increase in the share of the elderly in the population and the share of deaths within elderly age groups in the period 2018-2040 based on the main (medium) projection alternative from Statistics Norway. The growth in the share of the young elderly (65-79 years) is highest in the initial years in the period, while the share of the oldest old ( $\geq 80$ years) increases most in the latter part of the 2020 s. The share of deaths in the oldest old is projected to decrease markedly until the 2030s. Table 2 and Figure 2(b) together provide the results of the projections of HC and LTC costs, relative to the projections for 2018. These calculations indicate growth in health and care spending due to population ageing, as well as an upward-biased estimate if not properly adjusted for PTD.
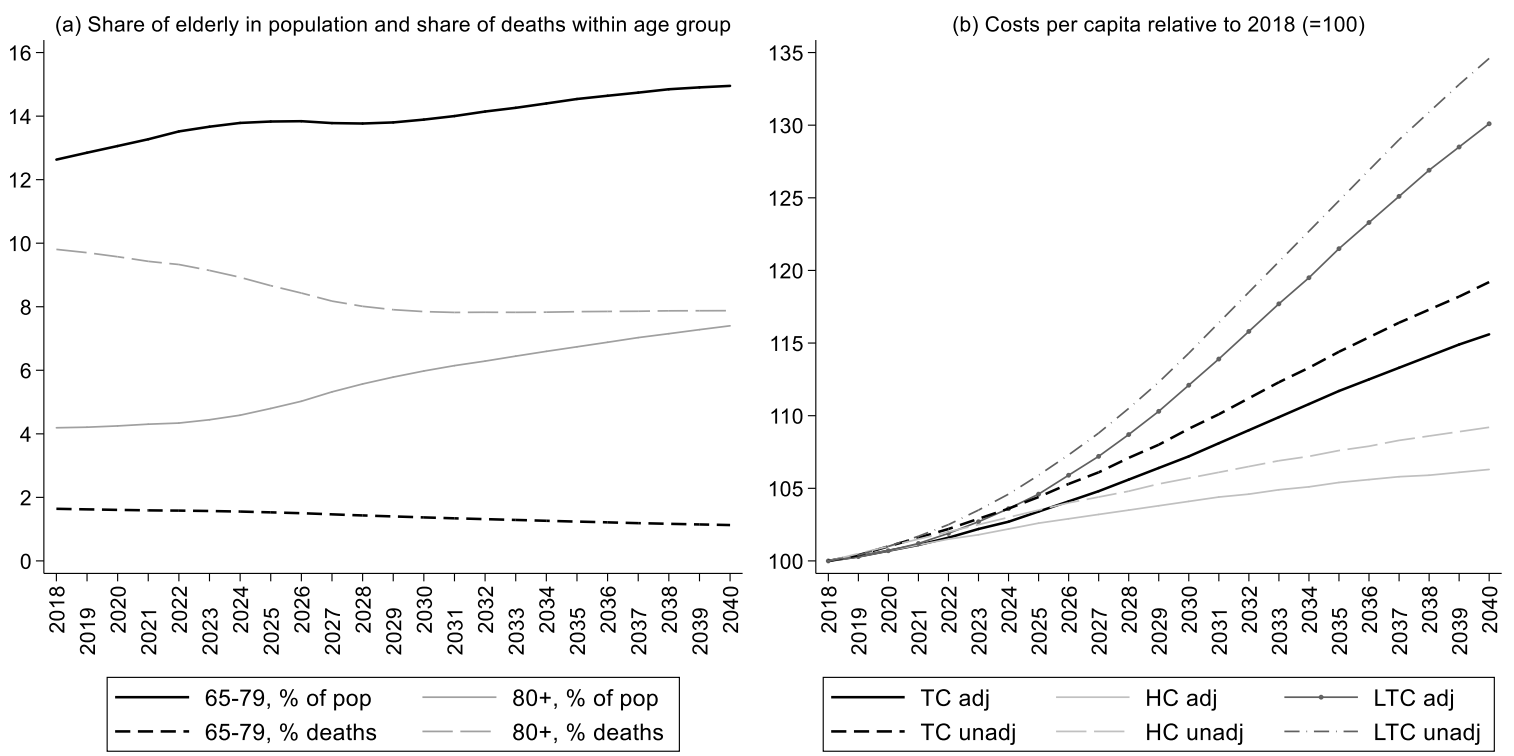

Figure 2: (a) Projected share of elderly and (b) projected per capita costs, 20182040. Unadjusted and adjusted for proximity to death (PTD)

Table 2: Projected per capita total costs (TC), health care (HC) costs and long-term care (LTC) costs. Percentage of total and annual increase from 2018. Unadjusted and adjusted for proximity to death (PTD)

\begin{tabular}{llllllllll}
\hline & & $2018-2025$ & $2025-2030$ & $2030-2040$ & $2018-2040$ \\
\cline { 2 - 11 } & & Total & Annual & Total & Annual & Total & Annual & Total & Annual \\
\hline Unadjusted & HC & 3.5 & 0.49 & 2.1 & 0.42 & 3.3 & 0.32 & 9.2 & 0.40 \\
& LTC & 5.9 & 0.82 & 8.0 & 1.55 & 17.7 & 1.65 & 34.6 & 1.36 \\
& TC & 4.4 & 0.62 & 4.5 & 0.88 & 9.2 & 0.89 & 19.2 & 0.80 \\
\hline Adjusted for PTD & HC & 2.6 & 0.36 & 1.5 & 0.30 & 2.1 & 0.21 & 6.3 & 0.28 \\
& LTC & 4.6 & 0.65 & 7.1 & 1.38 & 16.1 & 1.50 & 30.1 & 1.20 \\
& TC & 3.4 & 0.48 & 3.7 & 0.73 & 7.8 & 0.76 & 15.6 & 0.66 \\
\hline Upward bias in per capita & & & 2025 & & 2030 & & 2040 & & \\
costs (\%) (if ignoring PTD) & HC & & 1.9 & & 2.5 & & 3.7 & & \\
& LTC & 2.0 & & 2.9 & & 4.4 & & \\
& TC & & 1.9 & & 2.7 & & 4.0 & & \\
\hline
\end{tabular}


Adjusting for costs in the last year of life, the projected HC, LTC and TC costs in 2040 are $6.3 \%, 30.1 \%$ and $15.6 \%$ higher, respectively, than the projected per capita costs in 2018. This amounts to an annual growth in per capita costs of about $0.3 \%$ for $\mathrm{HC}, 1.2 \%$ for LTC and $0.7 \%$ for TC. The upward bias in 2040 per capita TC costs without correction for PTD is $4 \%$. The estimated growth rate of $\mathrm{HC}$ costs declines during the period, while the growth rate of LTC costs increases until the early 2030s when growth slows.

\section{Discussion}

\subsection{Decedent/survivor cost difference}

Comparing average costs during the last year of life with the average one-year HC and LTC costs of a person surviving at least two years, we find that decedent costs were on average 19 times higher than survivor costs. The relative difference (ratio) decreased with age for groups $\geq 30$ years, and was less than double for the oldest age group ( $\geq 100$ years). Hence, the first condition for a red herring effect, namely higher costs among decedents than survivors, was present in our cost estimates for Norway. Our evidence of declining ratios with age aligns with the findings of previous studies (Payne et al. 2007, Raitano 2006).

Higher estimated average costs among decedents than survivors were present for all services and age groups, except for medicine costs for those aged 90-99 years. However, the difference between decedents and survivors varied greatly between services, in both absolute and relative terms. In general, the cost ratio was smallest for services comprising the smallest proportions of TC, that is, GPs, medicine and mental health, but was still substantial in younger age groups for medicine and mental health. Relatively low ratios for GPs and medicine are also reported in other studies (Atella and Conti 2014, Moore et al. 2014, Hoover et al. 2002). The decedent/survivor ratio of per capita costs was lower for LTC than somatic care for all ages except for the age groups 70-84 years. However, as the average decedent is much older than the average survivor, the decedent/survivor ratio of average costs over all ages was higher for LTC than somatic care. For somatic costs, and hence HC costs, differences related to PTD were greater than those between age groups, while the age effect was more important for LTC. Thus, in line with previous research, the red herring effect was larger for HC than for LTC (McGrail et al. 2000, Martikainen et al. 2012, Hashimoto et al. 2010).

\subsection{Age patterns for average costs of decedents and survivors}

The age pattern for average $\mathrm{HC}$ costs found in our study - with decreasing decedent costs after the 50s, increasing survivor costs among the young elderly and decreasing costs among oldest old - resembles that found for similar services among the elderly in several countries (Bjørner and Arnberg 2012, Blakely et al. 2015, Gastaldi - Ménager et al. 2016, McGrail et al. 2000, Polder et al. 2006). However, some of these comparable studies do not report lower costs among the oldest old survivors (Colombier and Weber 2011, Werblow et al. 2007). We observe the same age pattern for GPs and medicine (Atella and Conti 2014, Moore et al. 2014). Mental health services had a divergent age pattern, with the highest costs among young adults, both for survivors and decedents.

Similar to previous studies, we found a strong age effect for LTC costs among the elderly for both decedents and survivors (de Meijer et al. 2011, Hashimoto et al. 2010, Häkkinen et al. 2008, Karlsson and Klohn 2014, Martikainen et al. 2012, McGrail et al. 2000, Polder et al. 2006, Werblow et al. 2007, Rolden et al. 2014, Hoover et al. 2002). While the absolute effect of age among the elderly was greater for decedents, the relative age effect, that is, the percentage increase with age, was greater for survivors. We also found relatively 
high and stable LTC costs among non-elderly decedents. Given that most comparable studies examined only the costs of the elderly, it is difficult to ascertain whether this result is specific to Norway.

In sum, we find that increasing LTC costs dominate the decreasing $\mathrm{HC}$ costs of elderly decedents, and that TC increase with age among the elderly for both decedents and survivors. The age profile of TC found in previous studies varies, and depends on the type of services and costs included, especially regarding LTC (Payne et al. 2007). Some studies exclude LTC altogether, while others exclude (fully or partly) the social care component of LTC costs. The reason for excluding social care can be deliberate; for example, the study follows the conventional definition of $\mathrm{HC}$ costs (cf. SHA/OECD), or a pragmatic definition, thereby reflecting the way services are organised and paid for. In many countries, the medical and social components of LTC are under the responsibility of different bodies, are paid for by different funds and are regulated by different laws. Even though the age effect is likely to be weaker if social care is excluded, the literature is ambiguous on the age effect for TC among the oldest old also when accounting for exclusion or inclusion of social care (Hashimoto et al. 2010, Hoover et al. 2002, Polder et al. 2006, Werblow et al. 2007, Häkkinen et al. 2008, McGrail et al. 2000). This reflects the potential influence of other social and cultural factors, such as the utilisation of private formal and informal care. Norway has been characterised as having strong alignment between old-age-related expenditures and elderly needs, with high level of both formal home-based and medical oriented institutional LTC (Damiani et al. 2011, Spasova et al. 2018, Daatland 2015).

\subsection{Decomposition of average costs}

The results show that LTC services are likely to substitute for HC services as age increases among both the deceased and survivors. User rates for medicine are lower among elderly decedents than for elderly survivors, which is likely to reflect higher rates of hospitalisation and nursing home admissions among decedents. Lower costs per user for GPs and medicine among the oldest old could indicate lower service intensity (e.g., fewer visits, less use of prescription drugs). Nevertheless, it also reflects that as age increases, an increasing share of the population moves into nursing homes during the year and so does not include the full year of costs as nursing homes typically cover the medical costs of their residents. Likewise, the sharply decreasing somatic costs per user with higher age among decedents, and not survivors, could reflect less treatment intensity in hospital care for dying patients as age increases, but also that terminally ill patients often transfer to nursing homes for end-of-life care. This supposition is supported by the fact that about $45 \%$ of people dying from cancer in Norway in 2011 died in a nursing home (Kalseth and Theisen 2017).

\subsection{Expenditure projections}

Because of a high projected decline in mortality rates among the elderly (the second condition for the red herring effect) and the relatively low increase in the share of the oldest old in the near future, our results suggest that the growth rate for $\mathrm{HC}$ costs due to demographic changes is highest at the beginning of the period and declines throughout, while the growth rate of LTC costs increases until the early 2030s when the demographic related growth will slow. We have also made projections using the low and high alternatives for the development of life-expectancy from Statistics Norway (boundaries in the 80-percent prediction interval (Syse et al. 2016)) which provide estimates for annual growth rates in the period 2018-2040 (adjusting for PTD) in the range of 0,27-0,29 for HC, 0,90-1,50 for LTC and 0,53-0,81 for TC. Higher improvement in life expectancy gives higher growth rates, especially for LTC, and higher upward bias if not adjusting for PTD. The upward bias 
in annual growth rates if not adjusting for PTD is relatively smaller for LTC than for HC reflecting the strong positive association between age and LTC costs among both elderly survivors and decedents.

\subsection{Strengths and weaknesses}

A strength of our study is that we compare average costs for the full year (365 days) before death for decedents with the one-year costs of survivors, as opposed to identifying deathrelated costs based on whether a person died or not during the year in which the costs are observed (Melberg et al. 2013). The latter would imply that we identify the costs for less than a full year for most deceased, but that some of the costs in the last year of life for people dying the following year would then be attributable to survivors. By comparing costs in the last year of life with annual costs with those alive at least two years after the year for which we observe the utilisation/costs, the problem of including death-related costs in survivor costs is substantially reduced, although probably not eliminated (Seshamani and Gray 2004). Another strength of this study is the decomposition of costs according to both the type of service and user rates and costs per user for the included services, thereby providing additional insights into the observed differences according to both age and PTD.

A weakness of this study is that we were unable to link data across service registries and hence were not able to study total user rates. The data on utilisation and numbers of unique users of long-term care for the total population and for survivors were prepared for us by Statistics Norway as aggregated numbers by age group, and hence we were only able to consider average costs and not any variation within the decedent and survivor age groups. Nor were the data on utilisation for the total population and for survivors linked with the population data. Hence, there could be some mismatch between the numerator and the denominator.

The data were collected as part of a broader study involving a number of complex data requirements. Hence, the process of extracting the data from the different registries became rather protracted, partly because of the very strict privacy regulations governing the long-term care data and the lack of experience in the registries and regulating authorities in delivering this type of complex data for research purposes. Hence, the data we use are for 2010, which while relatively recent when the process of applying for the data began, are now rather dated. The analyses are based on data from only one year. In our original dataset we had data from three consecutive years and the age pattern of utilisation was stable for the major service categories. Data availability at the time the data was collected prohibited the inclusion of data covering a longer period. Gregersen (2014) found increasing mortalityrelated somatic hospital expenditures over time using data for the period 1998-2009 for Norway. A recent Finnish study found that over a 10-year period (2000-2011), LTC was increasingly concentrated among decedents (Forma et al. 2017). If these findings are representative of developments during the last decade in Norway, then the decedent/survivor ratio would have increased relative to the situation we found in 2010 .

This study represents the first comprehensive comparison of health care and longterm care costs between decedents and survivors in Norway. As such, this study will be an important benchmark for future studies of the development following important reforms the last decade like the Coordination reform introduced in 2012 (Romøren et al. 2011).

Our study shows that not taking PTD in account could bias the interpretation and use of information of the age gradient in health spending. Likewise, PTD and age, are found, at least partly, to be proxies for morbidity (Carreras et al. 2018, von Wyl 2019, Howdon and Rice 2018). Hence, not taking health status as an independent factor into account could bias our results. There is still no consensus on whether higher longevity is associated with a 
compression or expansion of morbidity in old age and the findings vary with country, time period and the health indicator under study (Chatterji et al. 2015). The compression hypothesis tends to be supported by disability-related measures of morbidity, e.g. ADLfunctioning, whereas the expansion hypothesis tends to be supported by measures of chronic disease morbidity. This could point to an increase in the future need of $\mathrm{HC}$ and decrease in need of LTC compared to our projections (Lindgren 2016). The increasing prevalence and complexity of multi-morbidity (Pefoyo et al. 2015), typically increasing with age, could further increase costs, especially in social and inpatient care (Wang et al. 2018).

\section{Conclusion}

The population is ageing in Norway, as in many other countries around the world. Even though lower mortality rates are likely to contribute to dampening the expected increase in future spending on $\mathrm{HC}$ and LTC services due to the postponement of high death-related costs, especially for medical services, the age effect dominates, especially for LTC. The effect of an aging population on health spending differ by type of service depending on the relative importance of age vs PTD for per capita cost which itself varies with age. Hence, the timing of increase in HC vs LTC costs will vary depending on the timing of the changes in the demographic composition of the population.

\section{Author contribution}

JK conceptualized the study idea; JK and KSA prepared the data for analysis, JK conceptualized and conducted the analyses; JK drafted the manuscript; all authors commented for intellectual content and contributed to the drafting of the manuscript. All authors read and approved the final version of the manuscript.

\section{Acknowledgements}

The NPR, the IPLOS registry, the KUHR database, the Norwegian Prescription Database and the Cause of Death Registry provided the requisite data. The authors are solely responsible for the interpretations presented here.

\section{Funding}

The Research Council of Norway supported this work through the project 'Utilization of health care services at the end of life' (Grant No. 214298).

\section{References}

Atella, V. and Conti, V. (2014). The effect of age and time to death on primary care costs: The Italian experience. Social Science \& Medicine, 114, 10-17.

Bjørner, T. B. and Arnberg, S. (2012). Terminal costs, improved life expectancy and future public health expenditure. International journal of health care finance and economics, 12(2), 129-143.

Blakely, T., Atkinson, J., Kvizhinadze, G., Nghiem, N., McLeod, H., Davies, A. and Wilson, N. (2015). Updated New Zealand health system cost estimates from health events by sex, age and proximity to death: further improvements in the age of 'big data'. The New Zealand Medical Journal, 128(1422), 13-23.

Broad, J. B., Gott, M., Kim, H., Boyd, M., Chen, H. and Connolly, M. J. (2013). Where do people die? An international comparison of the percentage of deaths occurring in hospital and residential aged care settings in 45 populations, using published and available statistics. International journal of public health, 58(2), 257-67. 
Carreras, M., Ibern, P. and Inoriza, J. M. (2018). Ageing and healthcare expenditures: Exploring the role of individual health status. Health Economics, 27(5), 865-876.

Chatterji, S., Byles, J., Cutler, D., Seeman, T. and Verdes, E. (2015). Health, functioning, and disability in older adults - present status and future implications. The Lancet, 385(9967), 563575 .

Colombier, C. and Weber, W. (2011). Projecting health-care expenditure for Switzerland: further evidence against the 'red-herring' hypothesis. The International Journal of Health Planning and Management, 26(3), 246-63.

Daatland, S. O. (2015). Norwegian long - term care: Legacies, trends, and controversies. GIGAPP Estudios Working Papers, 3(1-7), 1-20.

Damiani, G., Farelli, V., Anselmi, A., Sicuro, L., Solipaca, A., Burgio, A., Iezzi, D. F. and Ricciardi, W. (2011). Patterns of Long Term Care in 29 European countries: evidence from an exploratory study. Bmc Health Services Research, 11(1), 316.

de Meijer, C., Koopmanschap, M., d'Uva, T. B. and Van Doorslaer, E. (2011). Determinants of long-term care spending: Age, time to death or disability? Journal of health economics, 30(2), 425-438.

de Meijer, C., Wouterse, B., Polder, J. and Koopmanschap, M. (2013). The effect of population aging on health expenditure growth: a critical review. European Journal of Ageing, 10(4), 353361.

Felder, S., Werblow, A. and Zweifel, P. (2010). Do red herrings swim in circles? Controlling for the endogeneity of time to death. Journal of health economics, 29(2), 205-212.

Forma, L., Aaltonen, M., Pulkki, J., Raitanen, J., Rissanen, P. and Jylhä, M. (2017). Long-term care is increasingly concentrated in the last years of life: a change from 2000 to 2011. European Journal of Public Health, 27(4), 665-669.

Forma, L., Rissanen, P., Aaltonen, M., Raitanen, J. and Jylhä, M. (2009). Age and closeness of death as determinants of health and social care utilization: a case-control study. European Journal of Public Health, 19(3), 313-318.

Fuchs, V. (1984). " Though much is taken": reflections on aging, health, and medical care. The Milbank Memorial Fund Quarterly. Health and Society, 62(2), 143-166.

Gastaldi - Ménager, C., Geoffard, P. Y. and de Lagasnerie, G. (2016). Medical spending in France: concentration, persistence and evolution before death. Fiscal Studies, 37(3-4), 499-526.

Gregersen, F. A. (2014). The impact of ageing on health care expenditures: a study of steepening. The European Journal of Health Economics, 15(9), 979-989.

Gregersen, F. A. and Godager, G. (2014). The association between age and mortality related hospital expenditures: Evidence from a complete national registry. Nordic Journal of Health Economics, $1(1)$.

Hagen, T. P., Amayu, K. N., Godager, G., Iversen, T. and Øien, H. (2011). Utviklingen $i$ kommunenes helse- og omsorgstjenester 1986-2010. HERO 2011: 5. Oslo: University of Oslo.

Hashimoto, H., Horiguchi, H. and Matsuda, S. (2010). Micro data analysis of medical and long-term care utilization among the elderly in Japan. International journal of environmental research and public health, 7(8), 3022-3037.

Hoover, D. R., Crystal, S., Kumar, R., Sambamoorthi, U. and Cantor, J. C. (2002). Medical expenditures during the last year of life: findings from the 1992-1996 Medicare current beneficiary survey. Health Serv Res, 37(6), 1625-1642.

Howdon, D. and Rice, N. (2018). Health care expenditures, age, proximity to death and morbidity: Implications for an ageing population. Journal of health economics, 57, 60-74.

Hyun, K. R., Kang, S. and Lee, S. (2015). Population Aging and Healthcare Expenditure in Korea. Health Economics, 25(10), 1239-1251. 
Häkkinen, U., Martikainen, P., Noro, A., Nihtilä, E. and Peltola, M. (2008). Aging, health expenditure, proximity to death, and income in Finland. Health Economics, Policy and Law, 3(02), 165-195.

Kalseth, J. and Theisen, O. M. (2017). Trends in place of death: The role of demographic and epidemiological shifts in end-of-life care policy. Palliative Medicine, 31(10), 964-974.

Karlsson, M., Iversen, T. and Øien, H. (2012). Scandinavian long-term care financing. In J. CostaFont and C. Courbage (Eds.), Financing long-term care in Europe: institutions, markets and models (pp. 254-278). New York: Palgrave Macmillan.

Karlsson, M. and Klohn, F. (2014). Testing the red herring hypothesis on an aggregated level: ageing, time-to-death and care costs for older people in Sweden. The European Journal of Health Economics, 15(5), 533-551.

Larsson, K., Kåreholt, I. and Thorslund, M. (2008). Care utilisation in the last years of life in relation to age and time to death: results from a Swedish urban population of the oldest old. European Journal of Ageing, 5(4), 349-357.

Lindgren, B. (2016). The Rise in Life Expectancy, Health Trends among the Elderly, and the Demand for Care-A Selected Literature Review. Working Paper 22521. National Bureau of Economic Research.

Marino, A., Morgan, D., Lorenzoni, L. and James, C. (2017). Future trends in health care expenditure. Health Working Papers, No. 95. Paris: OECD

Martikainen, P., Murphy, M., Metsä-Simola, N., Häkkinen, U. and Moustgaard, H. (2012). Sevenyear hospital and nursing home care use according to age and proximity to death: variations by cause of death and socio-demographic position. Journal of Epidemiology and Community Health, 66(12), 1152-1158.

McGrail, K., Green, B., Barer, M. L., Evans, R. G., Hertzman, C. and Normand, C. (2000). Age, costs of acute and long-term care and proximity to death: evidence for 1987-88 and 1994-95 in British Columbia. Age and Ageing, 29(3), 249-253.

Melberg, H., Godager, G. and Gregersen, F. (2013). Hospital expenses towards the end of life. Tidsskrift for den Norske laegeforening: tidsskrift for praktisk medicin, ny raekke, 133(8), 841844.

Moore, P. V., Bennett, K. and Normand, C. (2014). The importance of proximity to death in modelling community medication expenditures for older people: evidence from New Zealand. Applied health economics and health policy, 12(6), 623-33.

OECD (2017). Health at a Glance 2017: OECD Indicators. Paris: OECD Publishing.

Payne, G., Laporte, A., Deber, R. and Coyte, P. C. (2007). Counting Backward to Health Care's Future: Using Time - to - Death Modeling to Identify Changes in End - of - Life Morbidity and the Impact of Aging on Health Care Expenditures. Milbank Quarterly, 85(2), 213-257.

Pefoyo, A. J. K., Bronskill, S. E., Gruneir, A., Calzavara, A., Thavorn, K., Petrosyan, Y., Maxwell, C. J., Bai, Y. and Wodchis, W. P. (2015). The increasing burden and complexity of multimorbidity. Bmc Public Health, 15(1), 415.

Polder, J. J., Barendregt, J. J. and van Oers, H. (2006). Health care costs in the last year of life- the Dutch experience. Social Science \& Medicine, 63(7), 1720-1731.

Przywara, B. (2010). Projecting future health care expenditure at European level: drivers, methodology and main results. EconomicPapers 417 Directorate General Economic and Financial Affairs (DG ECFIN), European Commission.

Raitano, M. (2006). The impact of death-related costs on health care expenditure: a survey. ENEPRI Research Reports No. 17. Brussels: European Network of Economic Policy Research Institutes.

Rolden, H. J., van Bodegom, D. and Westendorp, R. G. (2014). Variation in the costs of dying and the role of different health services, socio-demographic characteristics, and preceding health care expenses. Social Science \& Medicine, 120, 110-117. 
Romøren, T. I., Torjesen, D. O. and Landmark, B. (2011). Promoting coordination in Norwegian health care. International journal of integrated care, 11(Special 10th Anniversary Edition).

Seshamani, M. and Gray, A. M. (2004). A longitudinal study of the effects of age and time to death on hospital costs. Journal of health economics, 23(2), 217-235.

Spasova, S., Baeten, R., Coster, S., Ghailani, D., Peña-Casas, R. and Vanhercke, B. (2018). Challenges in long-term care in Europe. A study of national policies. Brussels: European Social Policy Network (ESPN), European Commission.

Statistics Norway. StatBank. 11094 Projected probability of death (per 1000 ), by sex and age, in 3 $\begin{array}{lllll}\text { variants } & 2016 & - & 2100 & \text { [online], }\end{array}$ https://www.ssb.no/en/statbank/table/11094/?rxid=e6c8b6c8-9006-4dc1-b74165367e8bbbee].

Statistics Norway. StatBank. 11168 Population projections 1 January, by sex and age, in 9 variants $\begin{array}{llllll}(\mathrm{M}) & \text { (UD) } & 2016 & - & 2040 . & \text { [online], }\end{array}$ https://www.ssb.no/en/statbank/table/11168/?rxid=e6c8b6c8-9006-4dc1-b74165367e8bbbee].

Syse, A., Pham, D. Q. and Keilman, N. (2016). Befolkningsframskrivinger 2014-2100: Dødelighet og levealder [Population projections 2016-2100: Mortality and life expectancy]. Økonomiske analyser, 3(2016), 25-36.

van Baal, P. H. and Wong, A. (2012). Time to death and the forecasting of macro-level health care expenditures: Some further considerations. Journal of health economics, 31(6), 876-887.

von Wyl, V. (2019). Proximity to death and health care expenditure increase revisited: A 15-year panel analysis of elderly persons. Health economics review, 9(1), 9.

Wang, L., Si, L., Cocker, F., Palmer, A. J. and Sanderson, K. (2018). A systematic review of costof-illness studies of multimorbidity. Applied health economics and health policy, 16(1), 15-29.

Werblow, A., Felder, S. and Zweifel, P. (2007). Population ageing and health care expenditure: a school of 'red herrings'? Health Economics, 16(10), 1109-26.

Wong, A., van Baal, P. H., Boshuizen, H. C. and Polder, J. J. (2011). Exploring the influence of proximity to death on disease - specific hospital expenditures: a carpaccio of red herrings. Health Economics, 20(4), 379-400.

Yu, T. H.-K., Wang, D. H.-M. and Wu, K.-L. (2015). Reexamining the red herring effect on healthcare expenditures. Journal of Business Research, 68(4), 783-787.

Zweifel, P., Felder, S. and Meiers, M. (1999). Ageing of population and health care expenditure: a red herring? Health Economics, 8(6), 485-496.

(C) 2020 by the author(s). This article is an open access article distributed under the terms and conditions of the Creative Commons Attribution license (http://creativecommons.org/licenses/by/4.0/). 